\title{
Numerical Simulation of the Effects of Air Knives on Coating Thickness
}

\author{
Chengren-BAO ${ }^{1,2}$, Yonglin-KANG ${ }^{1}$, Yan-LI ${ }^{2}$ \\ (1. Materials Science and Engineering, University of Science and Technology Beijing, China \\ 100083; \\ 2. Shougang Jingtang United Iron \& Steel Co., Ltd.Hebei, China 063200)
}

\begin{abstract}
Key words: hot-dip galvanizing process; zinc layer thickness; numerical simulation
Abstract: A numerical simulation of airflow was conducted during the application of a protective zinc coating with air knife blowing. The simulation was conducted in combination with the air knife features on the hot-dip galvanizing line of the cold rolling mill of Shougang Jingtang United Iron \& Steel Co., Ltd. Fluent software was used in the simulation. This study also analyzed the effects of process parameters, such as air pressure, air blowing range, knife openness, and angle, on coating thickness. The effects of various factors on the numerical simulation of air pressure on the strip surface were regressed into a mathematical model. This method facilitated the quantitative analysis of such factors and provided a theoretical basis for precisely controlling coating thickness on the site.
\end{abstract}

\section{Introduction}

Air knives are critical for regulating coating thickness and uniformity in the hot-dip galvanizing process of cold-rolled strips ${ }^{[1-2]}$. At present, most modern hot-dip galvanizing lines and equipment in China are imported from abroad. Exploration into the mechanisms of air knifes that regulate coating thickness should analyze the effects of process parameters on coating thickness; these parameters include intake pressure, air blowing range, knife openness, and angle; such process will improve the accuracy and uniformity of coating thickness, reduce production costs, and increase product yield $\left.{ }^{[3,4}\right]$. The various process parameters that influence coating thickness are probed in this study by analyzing current air knife technologies. The working principle of air knives is explored through a numerical simulation. The effects of factors that influence the numerical simulation of air pressure on the strip surface are regressed into a mathematical model.

\section{Numerical simulation of coating thickness}

\section{Establishing a mathematical-physical model}

Inlet pressure $P_{0}$, air blowing range $Z$, knife openness $D$, conveyor speed $V$, and other air knife process parameters are the major factors that influence coating thickness. In this study, Fluent software, which is a global leader among current commercial computational fluid dynamics (CFD) series software, is adopted for analog simulation ${ }^{[5,6]}$. This software can be used to simulate and analyze fluid flow and heat transfer in areas with complex geometries. Fluent can also simulate sophisticated flow fields ranging from incompressible flow to moderately and highly compressible flow by using a variety of methods, such as multi-grid acceleration and convergence technologies, to achieve optimal convergence accuracy ${ }^{[7]}$. The grid-based $2 \mathrm{D}$ model established through a numerical simulation is a quad mesh with meshes refined at the air knife outlet near the wall with a total of approximately 200,000 meshes.

\section{Setting the boundary conditions}

The inlet is set as the pressure inlet within the pressure range of $15 \mathrm{kPa}$ to $50 \mathrm{kPa}$. The outlet is set as the pressure outlet connected to the atmosphere with a pressure of $101.325 \mathrm{kPa}$. Both the strip surface and the wall near the air knife are set as the boundary wall using the non-equilibrium wall 
function. The strip surface is set as a moving wall with a velocity of $0.5 \mathrm{~m} / \mathrm{s}$ to $2 \mathrm{~m} / \mathrm{s}$ in Fluent.

\section{Configuring the operating parameters of the air knife}

To explore the effects of the main process parameters on the actions of the air knife during galvanization, pressure distribution on the strip surface is simulated according to the actual operation parameters of air knife. The designed operation parameters of the air knives are provided in Table 1.

Table 1 Settings of Air Knife Operation Parameter

\begin{tabular}{cc}
\hline Parameter & Value \\
\hline Inlet pressure $P_{0} / \mathrm{kPa}$ & $15,20,25,30,35,40,45,50$ \\
Air blowing range $Z / \mathrm{mm}$ & $8,10,11,12,13,14,16,18,20,22$ \\
Knife openness $D / \mathrm{mm}$ & $1.0,1.2,1.4,1.6,1.8,2.0$ \\
Blowing angle $\alpha /\left(^{\circ}\right)$ & $-3,-2.5,-2,-1.5,-1,-0.5,0$ \\
\hline The working mechanisms of air knives may be characterized quantitatively by defining descriptive
\end{tabular}

The working mechanisms of air knives may be characterized quantitatively by defining descriptive indices, such as peak pressure $P_{\max }$, pressure half-value width $b$, and peak shearing stress $\tau_{\max }$. This approach is conducive to establishing the mathematical model for regulating coating thickness. $P_{\max }$ refers to the peak pressure on the strip surface under the blowing actions of air knives. A high peak pressure will result in strong air knife action during galvanization. The distance from the strip surface to the knife centerline when pressure attenuates to half of the peak value is denoted by $b$. A small value of $b$ will result in concentrated airflow and strong air knife actions during galvanization. The peak shearing stress on the strip surface is denoted by $\tau_{\max }$.

\section{Analysis of factors that influence coating thickness}

\section{Effects of the inlet pressure of air knives}

The inlet pressure of air knives is the most important process parameter and a key technical means of regulating coating thickness. Assuming that openness is a constant value $(D=1.2 \mathrm{~mm})$ and the range of inlet pressure $P_{0}$ is $15 \mathrm{kPa}$ to $50 \mathrm{kPa}$, the effects of varying inlet pressure values on the pressure distribution on the strip surface are analyzed by simulating three air blowing ranges, namely, 10, 14, and $18 \mathrm{~mm}$.
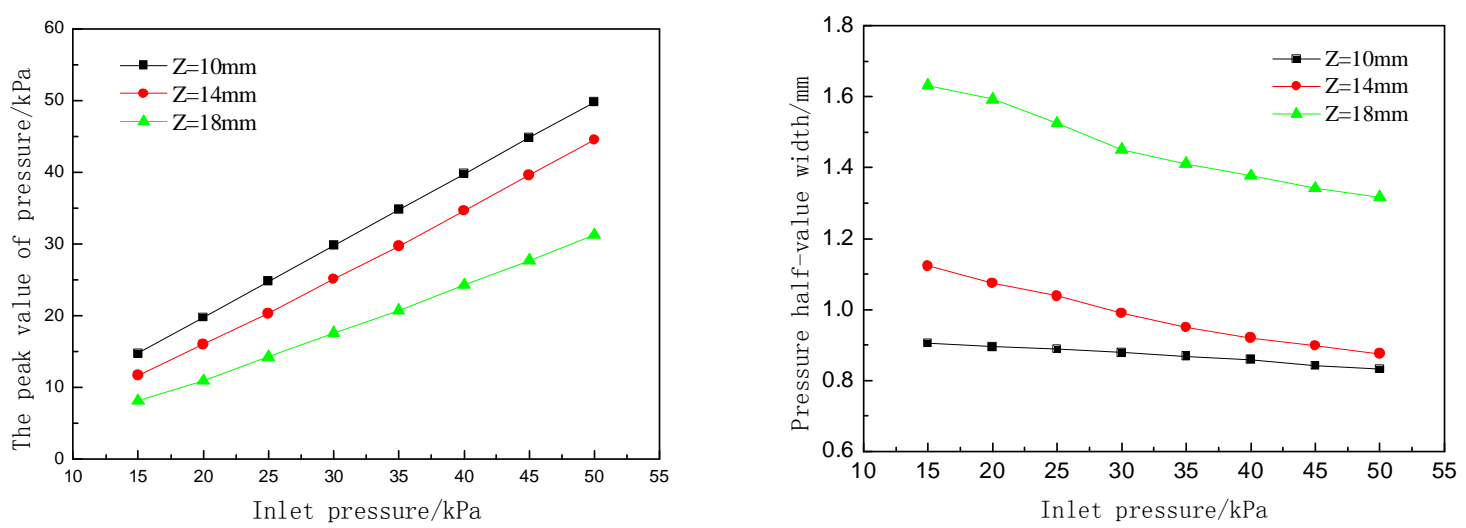

Fig.1 Relations of $\boldsymbol{P}_{\max }$ with the Inlet Pressure $\boldsymbol{P}_{\mathbf{0}} \quad$ Fig.2 Relations of $\mathrm{t} \boldsymbol{b}$ with the Inlet Pressure $\boldsymbol{P}_{\mathbf{0}}$

As shown in Fig.1-3, the peak pressure increases with the inlet pressure. An obvious linear relation is observed with increasing air blowing range $Z$ (distance from the knife to the strip surface). The peak pressure may undergo slight changes, and the pressure half-value width declines with increasing inlet pressure. The pressure half-value width may undergo significant changes with increasing air blowing range. The peak shearing stress increases with the inlet pressure, which exhibits a linear relation. The peak shearing stress may undergo slight changes with increasing air blowing range $Z$.

When the inlet pressure increases, the peak pressure and the peak shearing stress on the strip surface may increase linearly. The pressure half-value width decreases accordingly, which indicates that the outflow from the air knives is concentrated. Other factors remain unchanged. A high inlet pressure will result in a thin coating and strong air knife actions during galvanization. 


\section{Effects of air blowing range}

The effects of varying air blowing ranges on the pressure distribution on the strip surface are explored through analog computation. We assume that openness is a constant value $(D=1.2 \mathrm{~mm})$ and the air blowing range $Z$ is $8 \mathrm{~mm}$ to $22 \mathrm{~mm}$, which are then compared under different inlet pressure values $(20,30$, and $40 \mathrm{kPa})$ for air knives. As shown in Fig.4-6, the peak pressure $P_{\max }$ varies with the air blowing range $Z$, which has an inflection point of $Z=12 \mathrm{~mm}$. When the air blowing range is $Z<12$ $\mathrm{mm}$, the peak pressure undergoes a few changes. pressure is maintained at a high value because high-speed airflow does not diverge completely. When the air blowing range is $Z>12 \mathrm{~mm}$, the peak pressure begins to attenuate rapidly with increasing air blowing range. The actions of the air knife during galvanization also weakens sharply. The pressure half-value width $b$ varies with the air blowing range $Z$. When the air blowing range is $Z<12 \mathrm{~mm}$, the value of $b$ is maintained at roughly $0.9 \mathrm{~mm}$ with a small fluctuation. When the air blowing range is $Z>12 \mathrm{~mm}$, the value of $b$ begins to increase rapidly. For example, when $Z=10 \mathrm{~mm}$ at an inlet pressure of $30 \mathrm{kPa}$, the value of $b$ is $0.87 \mathrm{~mm}$. By contrast, when $Z=22 \mathrm{~mm}$, the value of $b$ may reach $1.98 \mathrm{~mm}$, which is 2.3 times higher than the aforementioned value, with serious air flow divergence. The peak shearing stress on the strip surface $\tau_{\max }$ varies with the air blowing range $Z$. When $8 \mathrm{~mm}<Z<20 \mathrm{~mm}$, the peak shearing stress gradually declines with increasing air blowing range $Z$.

In conclusion, when the air blowing range $Z$ is within the range of $8 \mathrm{~mm}$ to $12 \mathrm{~mm}$, the variation of the pressure distribution with increasing air blowing range is not evident. The pressure half-value width declines with less attenuation in the peak pressure on the strip surface. This result indicates concentrated airflow. Therefore, the actions of the air knife during galvanization are strong. When $Z>12 \mathrm{~mm}$, the peak pressure begins to attenuates rapidly with increasing air blowing range. The peak shearing stress also decreases, and the pressure half-value width increases, which indicates increased divergent airflow. Thus, air knife actions during galvanization weaken rapidly.

\section{Effects of knife openness}

The effects of different knife openness degrees on the pressure distribution on the strip surface are explored through analog computation. When the inlet pressure is $P_{0}=30 \mathrm{kPa}$ and the air blowing range is $Z=10 \mathrm{~mm}$, openness $D$ varies within the range of $1.0 \mathrm{~mm}$ to $2.0 \mathrm{~mm}$, thereby obtaining the calculation results. When knife openness is $D<1.2 \mathrm{~mm}$, the peak pressure on the strip surface is relatively low and the pressure on the strip surface is only approximately $27.35 \mathrm{kPa}$. However, when $D>1.2 \mathrm{~mm}$, the peak pressure on the strip surface is close to $30 \mathrm{kPa}$, with nearly no attenuation. The peak shearing stress $\tau_{\max }$ undergoes a slight change with knife openness $D$. The peak shearing stress reaches its maximum when $D=1.2 \mathrm{~mm}$.

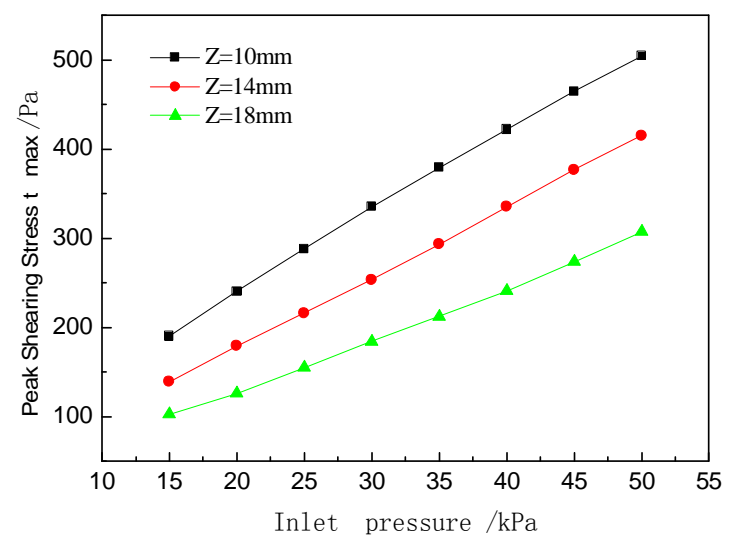

Fig.3 Relations $\tau_{\max }$ with the Inlet Pressure $\boldsymbol{P}_{0}$

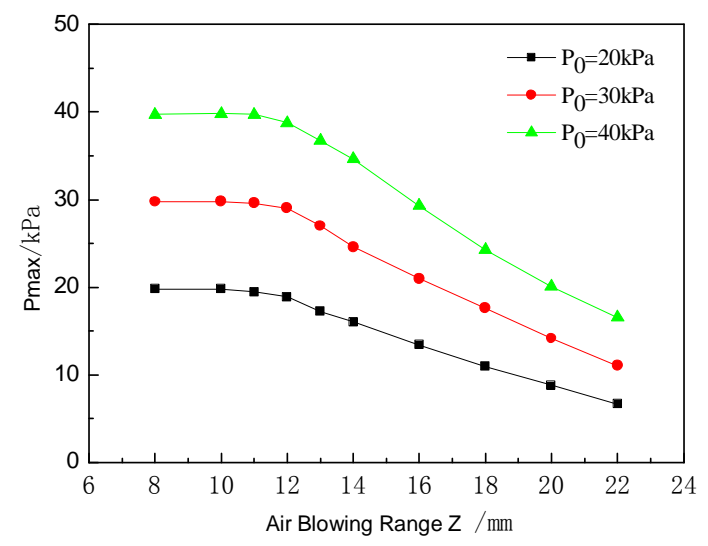

Fig.4 Relations of $\boldsymbol{P}_{\max }$ with the Air Blowing Range $Z$ 

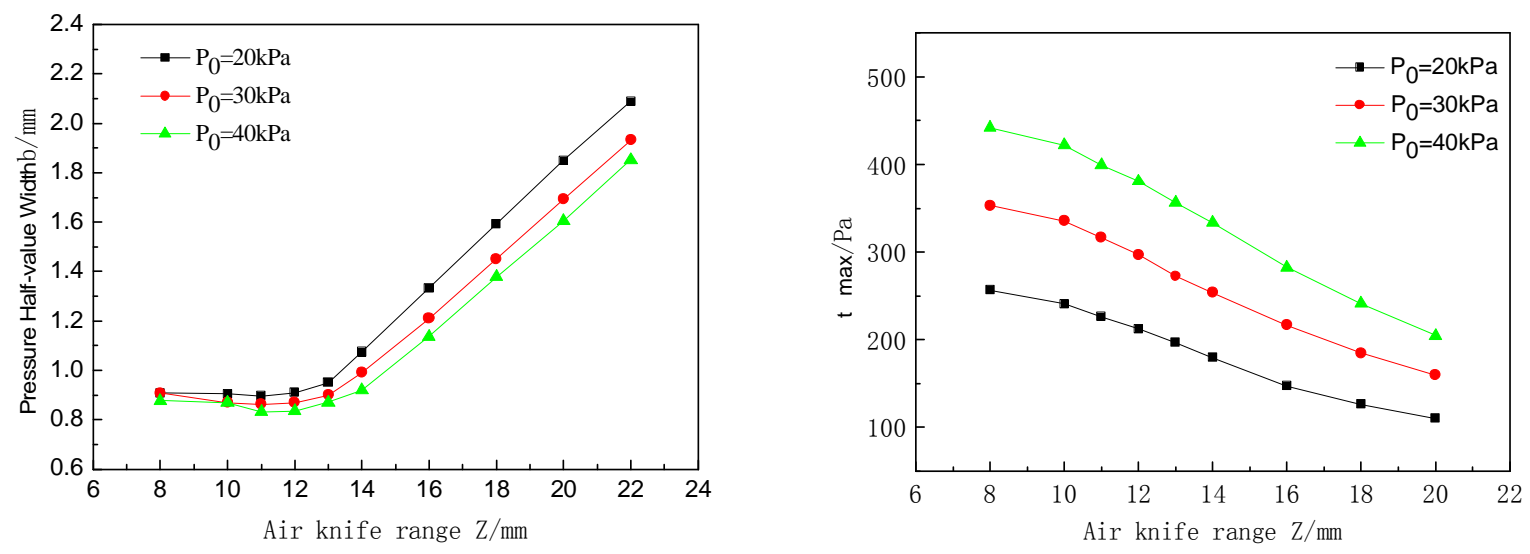

Fig.5 Relations of the $b$ with the Air Blowing Range $Z \quad$ Fig.6 Relations of $\boldsymbol{\tau}_{\max }$ with the Air Blowing Range $Z$

A uniform and stable airflow with small knife openness is required to ensure air knife action during galvanization. Openness $D$ should be within the range of 1.2 to 1.3 for the straight section of the air knife.

\section{Effects of blowing angle}

The effects of different blowing angles on the pressure distribution on the strip surface are explored through analog computation. When the inlet pressure is $P_{0}=30 \mathrm{kPa}$, the air blowing range is $Z=10 \mathrm{~mm}$ and openness is $D=1.2 \mathrm{~mm}$. The blowing angles are set to $-3^{\circ},-2.5^{\circ},-2^{\circ},-1.5^{\circ},-1^{\circ}$, $-0.5^{\circ}$, and $0^{\circ}$ to obtain the calculation results. The variations of the peak pressure $P_{\max }$ and the peak shearing stress $\tau_{\max }$ with the blowing angle $\alpha$ are shown in Fig.7. $P_{\max }$ increases slightly and the variation range of $\tau_{\max }$ decreases as the downward deflection angle of the air knife increases. Therefore, the pressure field on the strip surface undergoes slight changes. An air knife with a certain deflection angle has minimal effect on the pressure field on the strip surface.

\section{Regression analysis of coating thickness}

\section{Regression analysis of the peak pressure}

The pressure on the strip surface directly reflects the actions of the air knife during galvanization. The peak pressure on the strip surface is linearly correlated with blowing pressure and the Z/D segment. Therefore, the regression analysis of the peak pressure on the strip surface is conducted through the least-squares method to obtain the following regression model:

$$
\begin{array}{r}
P_{\max }=(1.0204-0.002169 \times Z / D) \times P_{0}-0.3244, \mathrm{Z} / \mathrm{D} \leq 9.5 ; \\
P_{\max }=(1.8005-0.07459 \times Z / D) \times P_{0}-2.6208,9.5 \leq \mathrm{Z} / \mathrm{D}<13.5 ; \\
P_{\max }=(1.6077-0.06242 \times Z / D) \times P_{0}-2.5067, \mathrm{Z} / \mathrm{D} \geq 13.5 .
\end{array}
$$

\section{Regression analysis of the pressure half-value width}

Classic concepts of jet (fluid) mechanics indicate that once the peak pressure on the strip surface and the pressure half-value width are provided, the pressure distribution in the longitudinal direction of the strip steel can be obtained. The pressure half-value width indicates the divergence of airflow to a certain extent. A small half-value width $b$ will result in concentrated airflow and improve air knife action during galvanization. The least-squares method is adopted for the regression analysis of the pressure half-value width. The regression model is given as

$$
\begin{array}{r}
b=\left(0.1836 \times Z+879.2595 \times D-2.5087 \times P_{0}-99.9696\right) / 1000, Z / D \leq 11 ; \\
b=\left(0.1614-0.0006395 \times P_{0}\right) \times Z / D-0.6550, Z / D>11 .
\end{array}
$$

As shown in the preceding analysis, the peak shearing stress is approximately linear with inlet 
pressure. The shearing stress regression model is established through the least squares method as follows:

$$
\begin{gathered}
\tau_{\max }=(11.9927-0.3640 \times Z / D) \times P_{0}+59.4125, Z / D \leq 9.5 ; \\
\tau_{\max }=(15.8878-0.6910 \times Z / D) \times P_{0}+21.9036,9.5 \leq Z / D<13.5 ; \\
\tau_{\max }=(14.4963-0.5785 \times Z / D) \times P_{0}+11.6029, Z / D \geq 13.5 .
\end{gathered}
$$

\section{Comparison of the fitted and measured values of the pressure}

The accuracy of the pressure calculated using the model is further confirmed via tablet-based numerical simulation. In the experiment, a steel plate is used as a substitute for a galvanized strip steel with a hole where a pressure gauge for testing pressure is connected via threaded and rubber pipes. Fig. 8 shows the comparison of the measured and fitted values of the pressure. The measured value is consistent with the fitted one.
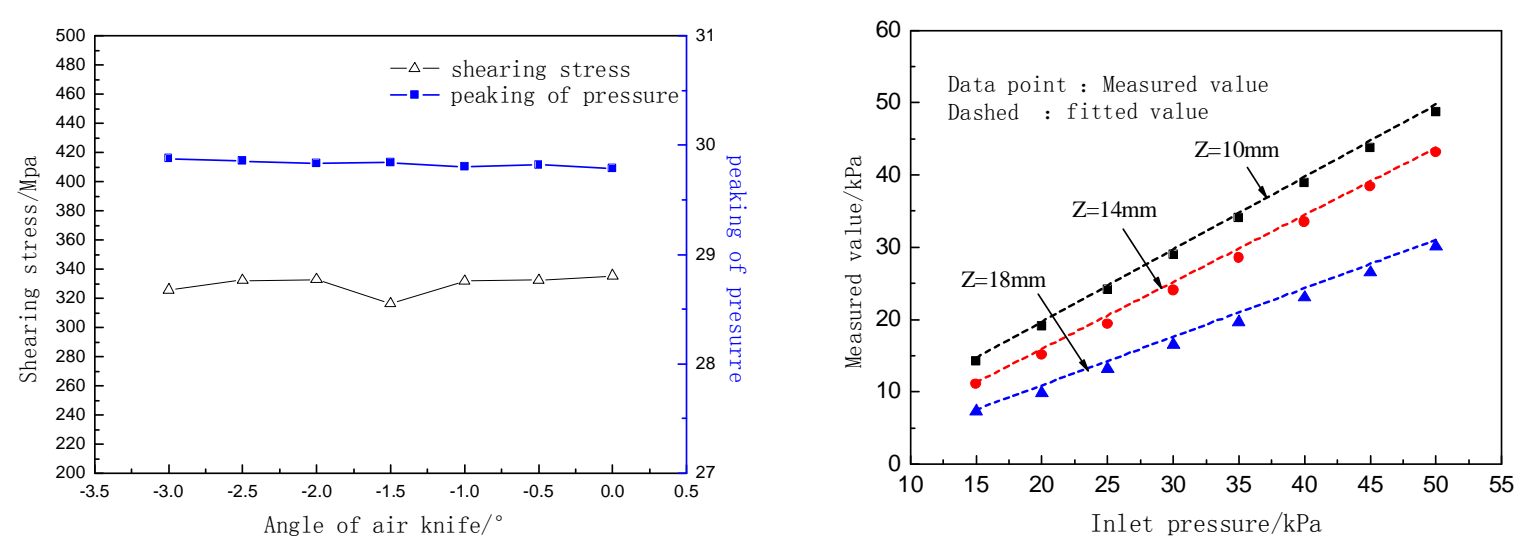

Fig.7 Relations of $\boldsymbol{P}_{\max }$ and $\tau_{\max }$ with the Angle $\alpha \quad$ Fig.8 Comparison of the Measured and Fitted Values

\section{Conclusions}

(1) The peak pressure and the peak shearing stress on the strip surface increase linearly with the inlet pressure $P_{0}$. Therefore, a high inlet pressure will result in strong air knife actions during galvanization.

(2) When the air blowing range $Z$ is $8 \mathrm{~mm}$ to $12 \mathrm{~mm}$, airflow is concentrated and the actions of the air knife during galvanization are strong.

(3) Openness $D$ should be maintained within the range of $1.2 \mathrm{~mm}$ to $1.3 \mathrm{~mm}$ with uniform and stable airflow to blow the liquid zinc.

(4) A small deflection angle of the air knife has minor effects on the pressure field on the strip surface, but can improve airflow on the edge of the strip steel. The blowing angle should be maintained within the range of $-0.5^{\circ}$ to $-2^{\circ}$.

(5) The effects of the factors that influence the numerical simulation of air pressure on the strip surface are regressed into a mathematical model for quantitative analysis. This approach provides a reference and basis for precisely regulating coating thickness.

\section{REFERENCE}

[1] Yonglin-Kang.Hot-rolled steel manufacture and production status quo analysis of our country in recent years [J]. Angang technology,2013,01(379):1-5.

[2] Qifu-Zhang,Bangjin-Liu,Jianzhong-Huang. Modern steel belt continuous hot-dip galvanizing[M]. Beijing, Metallurgical industry press,2007: 1-20.

[3] E. O. Tuck. Continuous coating with gravity and jet stripping. Physics of Fluids 26, 2352 (1983);

[4] Myrillas K, Gosset A, Rambaud P, et al. Technique for Delaying Splashing in Jet Wiping Process

[J]. Chem Eng Process, 2010,9(11): 5899 
[5]A.Gosset,.J.M.Buchlin. Jet Wiping in Hot-Dip Galvanization[J]. Journal of Fluids Engineering, 2007,129(4):466-475.

[6] Yoshiaki TAKEISHI,Hisakazu MORINO. Mechanism and Prevention of Edge Over Coating in Continuous Hot - dip Galvanizing[J]. ISIJ International,2000,40(11):1127-1133.

[7] K.J.AHN,M.K.CHUNG.A Noble Gas Wiping System to Prevent the Edge Overcoating in Continuous Hot-dip Galvanizing[J]. ISIJ International,2006,46(4):573-578. 